Reprod. Nutr. Dévelop., 1985, 25 (5), 883-893.

\title{
Purine-mediated phosphate influence on Artemia morphogenesis.
}

\author{
Arantxa HERNANDORENA
}

Laboratoire du Museum National d'Histoire Naturelle C.E.R.S., Plateau de l'Atalaye, 64200 Biarritz, France

Summary. Inorganic phosphate as well as organic phosphate in the form of glycerophosphate or pyrimidine nucleotides can be used by Artemia larvae to provide dietary purine bases and nucleosides with the phosphate required for their efficient utilization. Earlier results showed that purine nucleotides were efficiently metabolized without additional phosphate. The purine salvage pathway of Artemia is now established.

Basic nutritional research on Artemia purine requirement is especially interesting in developmental biology because larvae reared in purine-deficient cytidylic acid-rich nutritive media develop supernumerary gonopodes on the abdominal segments. The most efficient inducers of abdominal gonopodes are the guanine compounds (guanine, guanosine and guanylic acid) found to be least efficient to meet growth requirements. The relationship between growth rates and morphogenetic changes is not known. The specificity of a reduced purine:pyrimidine ratio in switching-on the expression of the genetic information coding for abdominal gonopodes is strengthened after showing that larvae reared in purinedeficient cytidylic acid-rich nutritive media did not develop abdominal gonopodes when cytidylic acid is used as a phosphate donor.

\section{Introduction}

As stressed by Gordon (1959), the biochemical peculiarities of an organism may make it ideal for research in a certain field; experiments that would be difficult or impossible with most other organisms, may be easy with a special one. Contrary to most organisms, the Utah strain of Artemia (Crustacea : Anostraca) is incapable of synthesizing the purine ring de novo (Clegg et al., 1967, Warner and McClean, 1968). This incapacity is expressed by an essential dietary purine requirement. Contrary to most eukaryotes, Artemia is equipped with a GMP. reductase (Renart and Sillero, 1974). The functioning of this enzyme could be inferred from the finding that guanylic acid, as well as adenylic acid or inosinic acid, is used by Artemia to satisfy its purine requirement (Hernandorena, 1972). In the same paper, I reported that the efficiency of purine bases and nucleosides was reduced as compared to that of nucleotides. It was not clear why nucleotides should be superior to bases or nucleosides since the former group of compounds 
are not transported efficiently across the cell membranes and probably must be converted to nucleosides or bases prior to entering the cells. The present results resolve this paradox and the purine salvage pathway of Artemia is established after showing that additional phosphate is required for the efficient utilization of purine bases and nucleosides.

Artemia purine requirement is of special interest because larvae reared in purine-deficient cytidylic acid-rich nutritive media develop supernumerary gonopodes on the abdominal segments (Hernandorena, 1970, 1977, 1979). The discovery that cytidylic acid can be used by Artemia larvae as a phosphate donor to increase the dietary efficiency of purine bases and nucleosides serves to strengthen the idea of the specificity af a reduced purine:pyrimidine ratio in switching-on the expression of the genetic information coding for abdominal gonopodes.

\section{Material and methods.}

The Utah strain and the method developed by Provasoli and d'Agostino (1969) for its axenic culture were used. The purine and pyrimidine supplies in each experiment have been indicated in the results. The pyrimidine requirement was met by cytidylic acid (CMP), except in one experiment using uridylic acid (UMP) instead of CMP, and thymidine was always omitted. The sources and qualities of the purines and pyrimidines used are presented in detail in table 1. The molecular weights have been included in order to compare the molar ratios. The concentrations are expressed in $\mathrm{mg}$ per $100 \mathrm{ml}$ of nutritive media ( $\mathrm{mg} \%$ ).

Culture conditions and analytical procedures are identical to those previously reported (Hernandorena, 1979). Twenty-five to one hundred animals were used for each experimental condition. The growth rate was expressed as a numerical index, defined by Provasoli and d'Agostino (1969), and very nearly approximates the number of moults. The growth index (Gl) is given for day 14. Morphogenesis was checked by microscopical examination of anesthesized animals.

\section{Results}

Figure 1 illustrates the difference in the ability of adenosine- $3^{\prime}-\left(2^{\prime}\right)$ phosphoric acid (AMP) and adenosine (AR) to satisfy the purine requirement of larvae reared in nutritive media containing a $20 \mathrm{mg} \%$ CMP concentration.

As seen in figure 2, growth rates increased with an AR supply increasing from 20 to $40 \mathrm{mg} \%$ only when the CMP concentration increased. When the CMP was replaced by UMP, the growth rates increased but to a lesser extent (fig. 3 ).

These results did not fit with my previous experiment on the interdependence of purine and pyrimidine requirements (Hernandorena, 1979). I suspected that the reduced efficiency of $A R$ as compared to AMP might result from a reduced phosphate availability and that CMP or UMP were serving as phosphate donors. In order to test this hypothesis, the glycerophosphosphate $\left(\mathrm{Na}_{2}-\beta\right.$-glycerophos- 


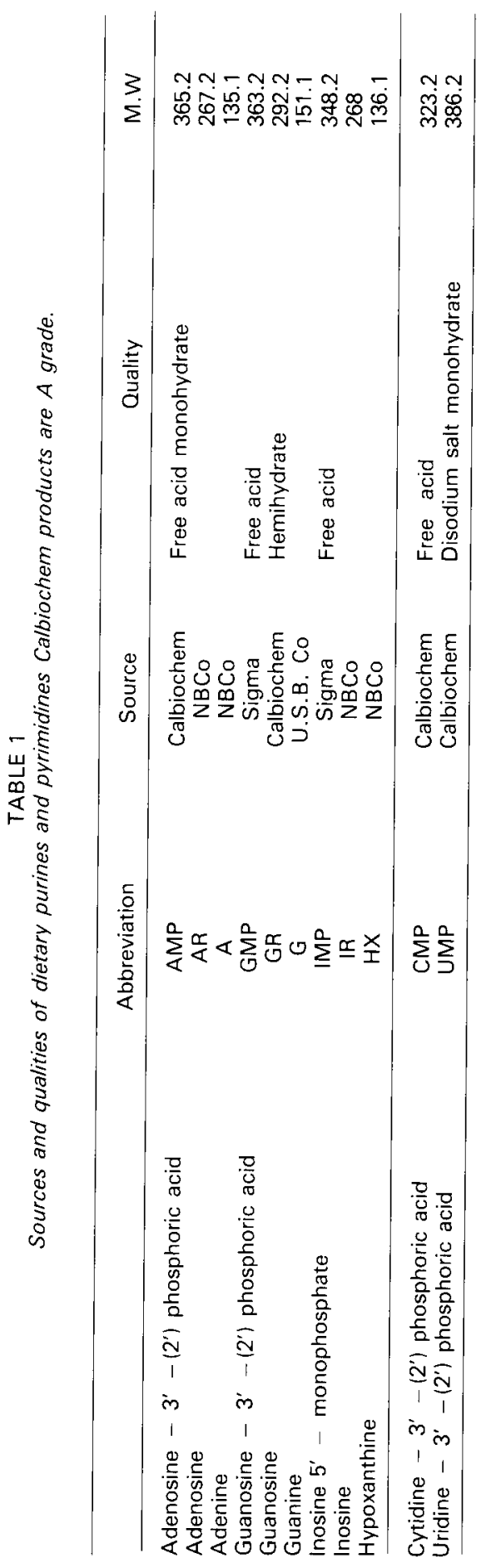



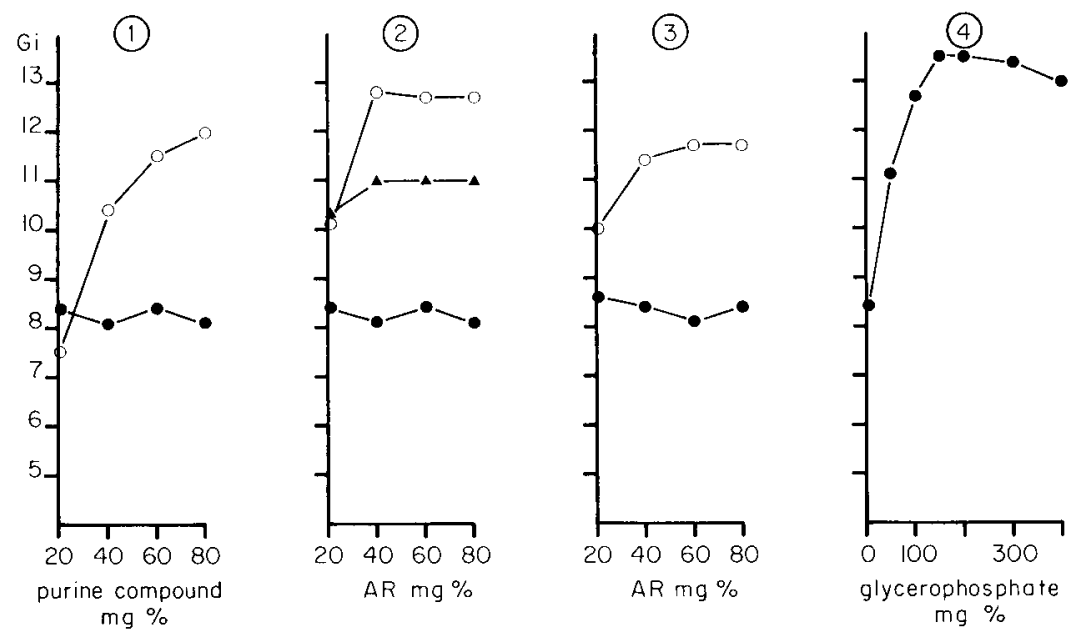

FIG. $1(*)$. - Dietary efficiency of AMP and $A R$

. $\mathrm{CMP}=20 \mathrm{mg} \%$.

FIG. 2. - Effect of CMP on AR efficiency. CMP $=20 \mathrm{mg} \%$ $\mathrm{CMP}=40 \mathrm{mg} \% \boldsymbol{\Delta} \boldsymbol{\Delta} ; \mathrm{CMP}=100 \mathrm{mg} \%$

FIG. 3. - Effect of UMP on AR efficiency. UMP $=20 \mathrm{mg} \%$ $\mathrm{UMP}=100 \mathrm{mg} \%$

FIG. 4. - Effect of glycerophosphate on AR efficiency. $A R=60 \mathrm{mg} \% ; C M P=20 \mathrm{mg} \%$.

phate pentahydrate) concentration of $50 \mathrm{mg} \%$ in the standard medium defined by Provasoli and d'Agostino (1969), was increased up to $400 \mathrm{mg} \%$. As seen in figure 4 , the growth rate of larvae reared in nutritive media containing $60 \mathrm{mg} \%$ AR and $20 \mathrm{mg} \% \mathrm{CMP}$ increased when the glycerophosphate concentration rose up to $150 \mathrm{mg} \%$. The ability of $A R$ to satisfy the purine requirement thus depended on phosphate availability.

That inorganic phosphate could also be used by Artemia larvae to increase the efficiency of $A R$ is shown in figures 5 and 6 . Sodium phosphate mono-H and potassium phosphate $\mathrm{di}-\mathrm{H}$ could serve as phosphate dunors. By increasing the salt concentration above those indicated, precipitation occurred and larval growth was impaired. Consequently, glycerophosphate was retained for further experiments. A standard glycerophosphate concentration of $50 \mathrm{mg} \%$ was always present in the nutritive media.

The efficiency of adenine (A) (fig. 7) was significantly increased by glycerophosphate, by that of guanine (G) was not (fig. 8).

The dietary efficiencies of the purine bases (fig. 9), nucleosides (fig. 10) and nucleotides (fig. 11) were compared in larvae grown under identical conditions i.e. with CMP constant at $20 \mathrm{mg} \%$ and with a constant additional glycerophosphate

(*) In all figures, the ordinate is the growth index (GI) for the 14th day of development. The abscissa is the concentration of the tested compounds expressed in $\mathrm{mg}$ for $100 \mathrm{ml}$ of nutritive media. 


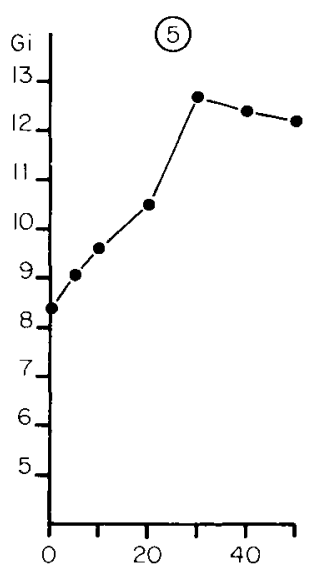

$\mathrm{NO}_{2} \mathrm{HPO}_{4} \mathrm{mg} \%$

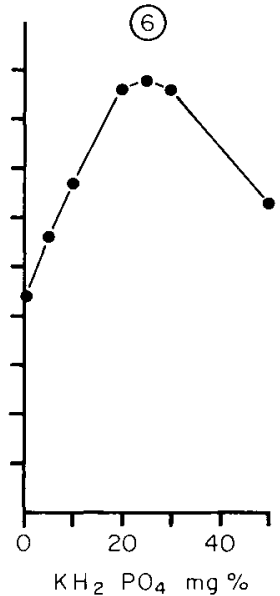

$\mathrm{KH}_{2} \quad \mathrm{PO}_{4}$ mg \%

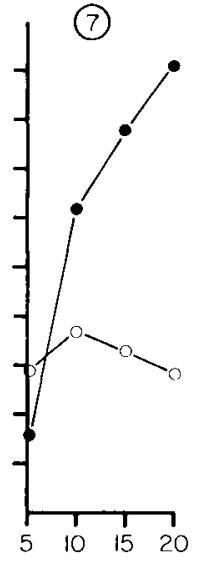

A $\mathrm{mg} \%$

FIG. 5. - Effect of sodium phosphate on AR efficiency. $\mathrm{AR}=60 \mathrm{mg} \% ; \mathrm{CMP}=20 \mathrm{mg} \%$.

FIG. 6. - Effect of potassium phosphate on AR efficiency. AR $=60 \mathrm{mg} ; \mathrm{CMP}=20 \mathrm{mg} \%$.

FIG. 7. - Effect of glycerophosphate on A efficiency. CMP $=20 \mathrm{mg} \%$. No addition glycerophosphate $=200 \mathrm{mg} \%$

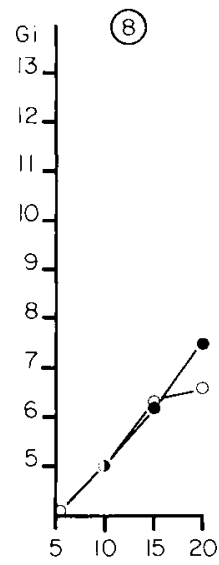

$G \mathrm{mg} \%$

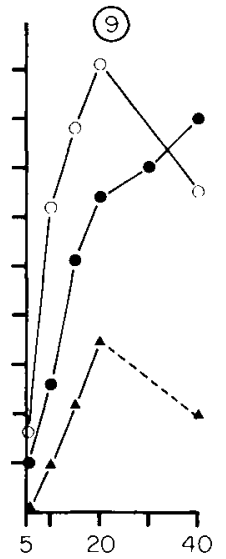

purine base $\mathrm{mg} \%$

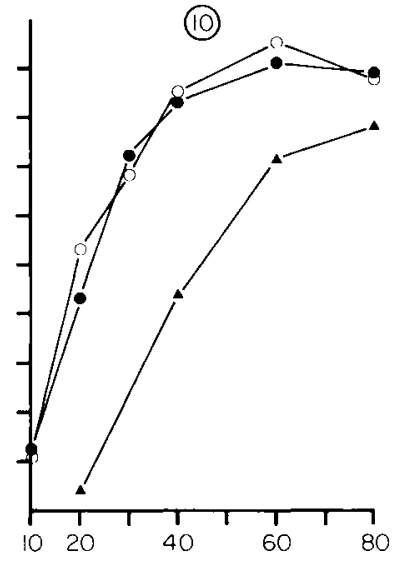

purine nucleoside $\mathrm{mg} \%$

FIG. 8. - Effect of g/ycerophosphate on $G$ efficiency. CMP $=20 \mathrm{mg} \%$. No addition glycerophosphate $=200 \mathrm{mg} \%$

FIG. 9. - Dietary efficiency of purine bases. CMP $=20 \mathrm{mg} \%$; glycerophosphate $=200 \mathrm{mg} \% ; \mathrm{A} ; \ldots$

FIG. 10. - Dietary efficiency of purine nucleosides. CMP $=20 \mathrm{mg} \%$; glycerophosphate $=200 \mathrm{mg} \% ; A R$ i 
supply $(200 \mathrm{mg} \%)$. On a molecular weight basis, A was the most efficient purine compound and $G$ the least efficient. If the $G$ concentration was increased to more than $20 \mathrm{mg} \%$ precipitation ensued and larval growth was impaired. Guanosine (GR) was less efficient than AR or inosine (IR), GMP was slightly less efficient than AMP or inosine $5^{\prime}$-monophosphate (IMP), but more efficient than GR. Differences among efficiencies are more important for bases than for nucleotides.

Besides growth rate, the induction of abdominal gonopodes by reduced purine:pyrimidine ratios was also used to measure the dietary purine efficiency. As seen in table 2, the most efficient inducers of abdominal gonopodes were purine compounds which were found to be the least efficient in meeting growth requirements.

When the purine requirement of Artemia is met by AMP, the quantitative CMP requirement for optimal growth rate increases with increasing the AMP

Table 2

Dietary efficiency of purine compounds measured by the percentage of animals bearing abdominal gonopodes.

\begin{tabular}{|c|c|c|c|c|c|c|c|c|c|}
\hline \multirow{2}{*}{$\begin{array}{c}\text { CMP }=20 \mathrm{mg} \% \\
\text { glycerophosphate } \\
200 \mathrm{mg} \%\end{array}$} & \multicolumn{3}{|c|}{ Bases $10 \mathrm{mg} \%$} & \multicolumn{3}{|c|}{ Nucleosides $20 \mathrm{mg} \%$} & \multicolumn{3}{|c|}{ Nucleotides $20 \mathrm{mg} \%$} \\
\hline & $\mathrm{G}$ & $H X$ & A & GR & IR & $A R$ & GMP & IMP & AMP \\
\hline $\begin{array}{c}\% \text { of animals } \\
\text { bearing abdominal } \\
\text { gonopodes }\end{array}$ & 80 & 57 & 6 & 100 & 16 & 20 & 62 & 33 & 54 \\
\hline
\end{tabular}
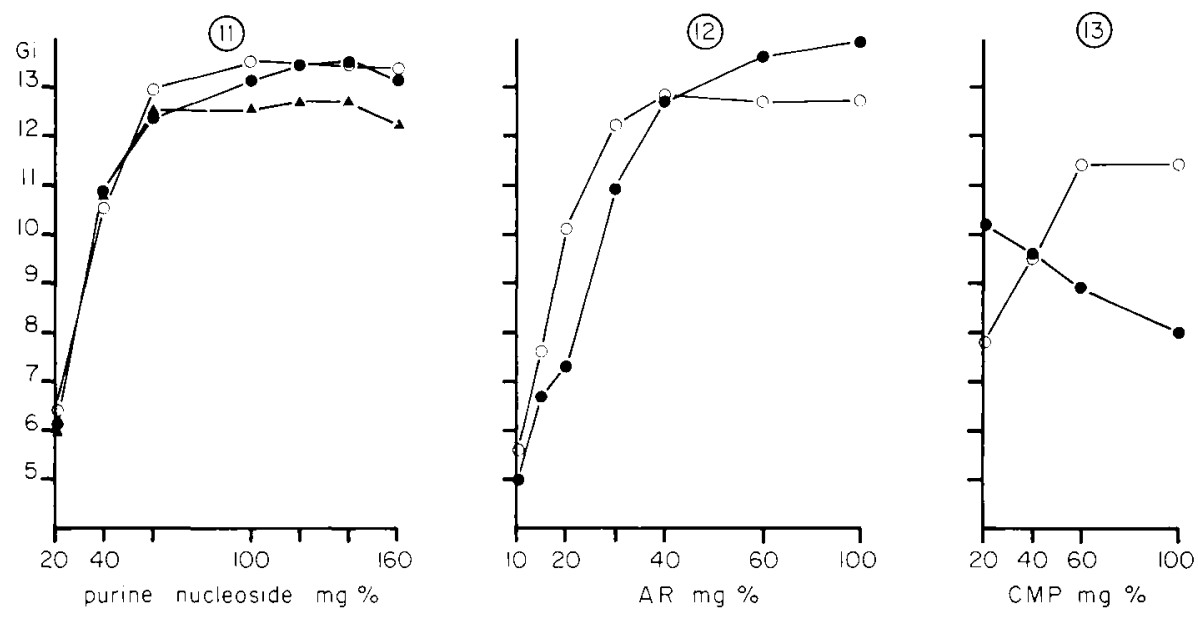

FIG. 11. - Dietary efficiency of purine nucleotides. CMP $=20 \mathrm{mg} \%$; glycerophosphate $=200 \mathrm{mg} \% ;$ AMP - ; IMP - GMP

FIG. 12. - Effect of g/ycerophosphate in relation to AR concentration in CMP-rich media. $\mathrm{CMP}=100 \mathrm{mg} \%$. No addition $\ldots$

FIG. 13. - Effect of glycerophosphate in relation to the CMP concentration in A-deficient media. $\mathrm{A}=10 \mathrm{mg} \%$. No áddition 
supply (Hernandorena, 1979). When the purine requirement is met by $A$ or by AR instead of by $A M P$ and the pyrimidine requirement by CMP, the metabolic fate of CMP must depend on the phosphate concentration of the diet. With no extra phosphate the growth rates of larvae reared in purine-rich media would be limited if part of the CMP supply was used to provide the base or the nucleoside with phosphate. With an extra phosphate source, growth should not be limited; on the contrary, the growth rates of larvae reared in purine-deficient CMP-rich media would be limited by an extra phosphate source. Our results (fig. 12) demonstrate this in larvae reared with CMP constant at $100 \mathrm{mg} \%$ and increasing $A R$ concentrations with or without additional glycerophosphate. The growth rate was limited by glycerophosphate supplementation when the larvae were reared in nutritive media containing 10 to $40 \mathrm{mg} \% A R$ and increased in nutritive media containing more than $40 \mathrm{mg} \% \mathrm{AR}$. With an AR concentration equal to or less than $15 \mathrm{mg} \%$, abdominal gonopodes were induced with or without extra phosphate. With AR concentration equal to or higher than $30 \mathrm{mg} \%$, no abdominal gonopodes were induced. With a $20 \mathrm{mg} \% \mathrm{AR}$ concentration, abdominal gonopodes were induced if CMP was not used as a phosphate donor, that is if CMP was concurrently supplied with glycerophosphate. With no extra phosphate supply, morphogenesis was normal (table 3).

The same conclusion was true when the purine requirement was met by $A$. When larvae were reared in adenine-deficient media $(A=10 \mathrm{mg} \%)$ with no extra phosphate, the growth rate increased with increasing the CMP supply; CMP served as a phosphate donor, and morphogenesis was normal. If CMP was concurrently supplied with an extra phosphate source, the growth rates of larvae reared in nutritive media containing excess CMP decreased (fig. 13). The percentage of larvae bearing abdominal gonopodes increased when the CMP supply was augmented (table 4).

Table 3

Influence of glycerophosphate on the percentage of animals bearing abdominal gonopodes. CMP constant at $100 \mathrm{mg} \%$.

\begin{tabular}{|c|c|c|c|c|}
\hline \multirow[b]{2}{*}{ glycerophosphate } & \multicolumn{4}{|c|}{ AR $\mathrm{mg} \%$} \\
\hline & 10 & 15 & 20 & 30 \\
\hline no addition & $\begin{array}{l}78 \\
75\end{array}$ & $\begin{array}{l}46 \\
43\end{array}$ & $\begin{array}{r}0 \\
22\end{array}$ & $\begin{array}{l}0 \\
0\end{array}$ \\
\hline \multirow{2}{*}{\multicolumn{5}{|c|}{ Table 4}} \\
\hline & & & & \\
\hline & \multicolumn{4}{|c|}{ CMP $\mathrm{mg} \%$} \\
\hline glycerophosphate & 20 & 40 & 60 & 100 \\
\hline no addition & 0 & 0 & 0 & 0 \\
\hline $200 \mathrm{mg} \%$ & 6 & 7 & 50 & 67 \\
\hline
\end{tabular}




\section{Discussion}

Little is known about the processes which control the anamorphic pattern of development of the Anostraca and, as stressed by Fryer (1983), dietary studies in Artemia can provide clues to understand how this pattern is established and controlled. Developmental and evolutionary considerations have been developed recently (Hernandorena, 1985).

The present results show that purine bases (except guanine) and purine nucleosides can satisfy the purine requirement of Artemia, if concurrently supplied with additional phosphate. Inorganic phosphate as well as organic phosphate in the form of glycerophosphate, CMP or UMP may be used as phosphate donors; they supply the bases and the nucleosides with the phosphate required for their efficient utilization. Identical growth rates $(\simeq 12.8)$ are achieved by larvae reared in nutritive media containing $60 \mathrm{mg} \%$ adenosine and either $100 \mathrm{mg} \% \mathrm{CMP}, 20 \mathrm{mg} \%$ CMP plus $100 \mathrm{mg} \%$ glycerophosphate, 20 mg \% CMP plus $25 \mathrm{mg} \% \mathrm{KH}_{2} \mathrm{PO}_{4}$, or $20 \mathrm{mg} \%$ CMP plus $30 \mathrm{mg} \% \mathrm{Na}_{2} \mathrm{HPO}_{4}$ $12 \mathrm{H}_{2} \mathrm{O}$. Inorganic phosphate is thus more efficiently utilized than organic phosphate. But higher growth rates $(\simeq 13.5)$ can be achieved with a $60 \mathrm{mg} \%$ adenosine concentration if the phosphate supply is increased using glycerophosphate or CMP but not when using inorganic salts due to precipitation.

It was previously shown that inorganic phosphate is directly taken up and incorporated into acid-soluble organic phosphorous compounds by Artemia adults (California strain) reared with undefined food (Kobayashi et al., 1972). The present results show that organic phosphate is also used. McLaughlin and Zahl (1959) demonstrated that nucleotides can serve as phosphate donors in marine algae. Alkaline phosphatases firmly bound to the algal cell surface split AMP and glycerophosphate at the same rate as glucose-6-phosphate, indicating that a similar uptake mechanism operates for all three compounds (Zuengler and Perras, 1965). Alkaline phosphatases found in Artemia guts (Bianchi and Pirodda, 1968) could play such a role.

Bases are salvaged via ribosyltransferases. Since adenine is more efficient than hypoxanthine, the activity of adenine phosphoribosyltransferase is possibly higher than that of hypoxanthineguanine phosphoribosyltransferase (HGPRT). The reduced efficiency of guanine as compared to hypoxanthine cannot be explained by a reduced HGPRT activity since the same enzyme is used to salvage both guanine and hypoxanthine. It cannot be explained either by a reduced GMPreductase activity since guanosine and guanylic acid are more efficiently metabolized than guanine. It is possible that in Artemia as in Drosophila the major fate of guanine is the catabolic pathway; the low solubility of guanine may also affect its uptake (Johnson et al., 1980).

Adenosine and inosine are respectively equally efficient and more efficient than guanosine. In view of our results on the ammonia excretion rates of Artemia (Hernandorena and Kaushik, 1983), adenosine may first be deaminated to inosine. 
The fact that inosine $5^{\prime}$-monophosphate can satisfy the purine requirement as well as adenosine $2^{\prime}-3^{\prime}$-monophosphate (mixed isomers) suggests that nucleotides are converted to nucleosides by non-specific phosphatase, regardless of the position of the phosphate $\left(2^{\prime}, 3^{\prime}, 5^{\prime},\right)$, rather than by specific nucleotidases.

The purine compounds found to be least efficient in meeting growth requirements are the most efficient inducers of abdominal gonopodes. These are guanine among the bases, guanosine among the nucleosides and guanylic acid among the nucleotides; differences in molecular weight (table 1) cannot explain the observed discrepancies (table 2). The relationship between growth rate and morphogenetic change is not known. Supernumerary gonopodes were induced for the first time on Artemia larvae reared in an adenylic acid-deficient medium containing a standard pyrimidine supply. The adenylic acid deficiency reduced growth and survival rates (Hernandorena, 1970). Pyrimidine deletion restored normal morphogenesis in larvae reared in an adenylic acid-deficient medium. Pyrimidine deletion had no effect on growth rate but increased survival rate (Hernandorena, 1977). It was further shown that excess cytidylic acid increased the adenylic acid concentration threshold inducing abdominal gonopodes (Hernandorena, 1979). It became evident that a purine:pyrimidine imbalance was involved. The finding that cytidylic acid can be used by Artemia larvae to increase the dietary efficiency of purine bases and nucleosides served to strenghten the idea of the specificity of the purine:pyrimidine imbalance. If part of the cytidylic acid supply is used to provide adenine or adenosine with phosphate, abdominal gonopodes are not induced on larvae reared in a purine-deficient cytidylic acidrich medium. If an identical cytidylic acid supply is fed concurrently with an extra phosphate source, abdominal gonopodes are induced. It appears that when larvae are reared in a glycerophosphate-deficient medium, cytidylic acid is deviated from its " normal " metabolic fate and utilized as a phosphate donor. This " normal " metabolic fate could be the production of deoxyuridylate, the substrate of thymidylate synthetase, because pyrimidinedeoxynucleosides have been found to be the most efficient inducers of abdominal gonopodes when given in excess in relation to the purine supply (Hernandorena and Kaushik 1985).

The uniqueness of Artemia, in its incapacity to synthesize the purine ring de novo makes it possible to divorce purine biosynthesis from thymidylate biosynthesis. This cannot be done in most organisms, including insects, because folic acid is involved in both purine and thymidylate biosynthesis. Among insects, a requirement for nucleic acids or components thereof is virtually restricted to Diptera in which all degrees of needs from nonrequirement to absolute essentiality, is documented. Requirements are usually satisfied by nucleotide mixtures (Dadd, 1977). Apart from growth inhibitory effects, morphogenetic effects due to purine: pyrimidine imbalances have not been reported. The use of Artemia in basic nutritional research on the purine requirement offers many advantages and a special point of interest in developmental biology. 
Résumé. Implication du phosphate sur l'effet morphogénétique des purines chez Artemia (Crustacé : Anostraca).

Contrairement aux nucléotides, les bases et les nucléosides puriques ne sont efficacement métabolisées par les larves d'Artemia que si le milieu nutritif est enrichi en phosphate. Le phosphate inorganique et le phosphate organique sous forme de glycérophosphate ou de nucléotides pyrimidiques sont utilisés. L'étude du besoin alimentaire d'Artemia en dérivés puriques présente un intérêt particulier dans le domaine de la biologie du développement, car les larves élevées dans des milieux nutritifs déficients en purine et riches en acide cytidylique développent des appendices génitaux surnuméraires sur les segments abdominaux normalement apodes. Les meilleurs inducteurs d'appendices abdominaux, la guanine, la guanosine et l'acide guanylique sont les dérivés puriques les moins aptes à satisfaire les besoins de la croissance. La relation entre le taux de croissance et l'effet morphogénétique reste à déterminer. La spécificité du rapport purine : pyrimidine dans le déclenchement de l'expression de l'information génétique qui code la morphogenèse des appendices abdominaux surnuméraires est mise en évidence par la non-induction de l'effet morphogénétique chez des larves élevées dans des milieux nutritifs déficients en purine et riches en pyrimidine si l'acide cytidylique est utilisé comme donneur de phosphate.

\section{References}

BIANCHI U., PIRODDA G., 1968. Enzyme interactions in homogenates of parthenogenetic Artemia salina. Alterations of the electrophoretic patterns of some alkaline phosphomonoesterases. Riv. Biol. Univ. Perugia, 21, 585-588

CLEGG J. S., WARNER A. H., FINAMORE J. F., 1967. Evidence for the function of $\mathrm{P}^{1}, \mathrm{P}^{4}-$ diguanosine $5^{\prime}$-tetraphosphate in the development of Artemia salina. J. biol. Chem., 242. 1938-1967.

DADD T. H., 1977. Quantitative requirements and utilization of nutrients : Insects. In CRC Handbook in nutrition and food., Sect. D. Nutritional requirements, vol. I, 305-346 (Ed. M. RECHCIGL Jr.) CRC Press.

FRYER G., 1983. Functional ontogenetic changes in Branchinecta ferox (Milne-Edwards) (Crustacea : Anostraca). Phil. Trans. roy. Soc. Lond. B, 303, 229-343.

GORDON H. T., 1959. Minimal nutritional requirements of the German roach Blattela germanica L. Ann N. Y. Acad. Sci., 77, 290-351.

HERNANDORENA A., 1970. Obtention de morphogenèses appendiculaires abortive et surnuméraire chez Artemia salina L. (Crustacé Branchiopode) par carences alimentaires de base pyrimidique et de nucléotide purique. C. R. Acad. Sci. Paris, sér. D, 271, 1406-1410.

HERNANDORENA A., 1972. Signification morphogénétique du besoin alimentaire en acides nucléiques chez Artemia salina II. Besoin en dérivés puriques. Arch. Zool. exp. gén., 113, 489-498.

HERNANDORENA A., 1977. Action antagoniste de nucléotides puriques et pyrimidiques alimentaires sur la morphogenèse appendiculaire d'Artemia salina (L.) (Crustacé Branchiopode). C.R. Acad. Sci. Paris, 284, 1337-1339.

HERNANDORENA A., 1979. Relationships between purine and pyrimidine dietary requirements and Artemia salina morphogenesis. Comp. Biochem. Physiol., 62 B, 7-12.

HERNANDORENA A., 1985. Action de la methionine alimentaire sur la morphogenèse appendiculaire d'Artemia. Hypothèse sur l'évolution du phénotype de ce crustacé. Reprod. Nutr. Dévelop., 25, 75-81.

HERNANDORENA A., KAUSHIK S. J., 1983. Effect of quality and quantity of dietary purines on ammonia excretion rates of Artemia sp. Comp. Biochem. Physiol, 76 B, 637-641.

HERNANDORENA A., KAUSHIK S. J., 1985. Effect of quality and quantity of dietary pyrimidines on ammonia excretion rates of Artemia sp. Comp. Biochem. Physiol. in press.

JOHNSON M. M., NASH D., HENDERSON J. F., 1980. Metabolism of guanine and guanosine in larvae of Drosophila melanogaster. Comp. Biochem. Physiol., 66 B, 563-567. 
KOBAYASHI K., SAITA Y., TOMIYAMA T., 1972. Incorporation of $32 \mathrm{PO}_{4}$ directly taken up into acid-soluble phosphates of Artemia salina. Mar. Biol., 12, 295-299.

McLAUGHLIN J. J. A., ZAHL P. A., 1959. Axenic zooxanthellae from various invertebrate hosts. Ann. N. Y. Acad. Sci., 77, 55-72.

PROVASOLI L., d'AGOSTINO A., 1969. Development of artificial media for Artemia salina. Biol. Bull., 136, 434-453.

RENART M. F., SILLERO A., 1974. GMP-reductase in Artemia salina. Biochim. biophys. Acta, 341, 178-186.

WARNER A. H., MCCLEAN D. K., 1968. Studies on the biosynthesis and role of diguanosine tetraphosphate during growth and development of Artemia salina. Develop. Biol., 18, 278293.

ZUENGLER E. J., PERRAS J. P., 1965. Phosphatases in marine algae. Biol. Bull., 128, $271-284$. 